\title{
INVESTIGATING THE CULTURAL LANDSCAPE IDENTITY OF JEDDAH, KSA
}

\author{
TAREK SAAD RAGAB ${ }^{1,2}$ \\ ${ }^{1}$ Faculty of Architecture and Design, Effat University, KSA \\ ${ }^{2}$ Faculty of Engineering, Alexandria University, Egypt
}

\begin{abstract}
This paper is one of a series that aims to invigorate the debate over challenges to the cultural landscape identity of the primate Arab cities. Focusing on metropolitan Jeddah, the paper addresses the nature of the current cultural landscape identity and the persistent "Exoticization" of the city's image induced by the rejection of the traditional urban vocabulary and the adoption of imported design and planning models that are mostly diversified and contextually odd. A desktop analysis provides evidence for general cultural identity confusion and identity conflict. The research attempts to answer two major questions: what are the reasons behind the city's cultural consumerism pattern and the resulting blurring of identity? And, is there a cultural identity conflict among the society sects responsible for forming the city's character? The research argues that the endangerment to an intact cultural-landscape-identity formation is attributed to a change in the community's collective mindset in terms of the interpretation of "identity" and "locality" and the links between "modernity" and "Westernization". The research documents some attempts to adopt a regionally inspired design approach that reflects local values and a sustainable model, which empowers local cultural landscape identity and, at the same time, could be accepted by most of the community.
\end{abstract}

Keywords: cultural landscape, cultural identity, urban configuration, Jeddah, KSA.

\section{INTRODUCTION}

This paper revisits the cultural landscape and the identity conflict and loss of the primate cities in the Arab region. The first work, titled "Conflict at the Sea: The Crisis of Cultural Identity in Rehabilitating Historic Beirut Downtown", tackled the loss of the local built-up cultural landscape identity of old downtown Beirut and the rehabilitation process during the reconstruction of Beirut following the Lebanese Civil War 1975-1990 [1]. This work aims to invigorate the debate over the additional challenges in maintaining an intact built-up cultural landscape and homogenous identity of one important primate Arab city: Jeddah, in the Kingdom of Saudi Arabia (KSA). It addresses the driving factors that have led, and are still leading, to the empowerment of the traditional cultural landscape transformation, and that are articulating its discrepant and ambiguous nature. The methodology uses Hofstede's Cultural Identity Theory [2] and includes the analysis of the specific links between the related cultural dimensions of Saudi society and the cultural landscape transformation and identity confusion.

Since the secret endorsement of the 1916 Sykes-Picot Agreement following the collapse of the Ottoman Empire, which allocated the region's colonized zones among the victorious allies, the lives of Arabs have been in a constant state of change - socially, economically, politically, and physically (Fromkin [3], Sicker [4]). The reign of the Western system, enforced by colonization power, triggered actions for change in the newly divided Arab countries. The pace of change has been inconsistent and has increased amidst the political liberation movement and the start of the exploitation of the region's most precious natural resources of the nascent Arab nations: oil and natural gas. Additionally, the global communication revolution and the domination of the global open-market economy accelerated the pace of such transformation. One phenomenon that describes the intensity of 
such a transformation is the drastic change of morphology, pattern, and other elements of the cultural landscape of the Arab primate cities, where the old parts of cities remained intact but represented the blighted and abandoned districts of the rapidly grown cities. The expansions of these cities have been vastly different in their configurations and spatial patterns, as the old parts structure a different identity for each city, generally marked as inconsistent, blurred, and confusing.

\section{THE URBAN CULTURAL LANDSCAPE}

\subsection{Cultural landscape identity}

Cities are the greatest human product and the utmost expression of human culture. The ICOMOS Symposium held in 2004 concentrated on cultural landscape identification in the form of the "mutual interaction of people and nature over time" [5]. It recognized continuously evolving landscapes as "where people and nature dwell together". The cultural landscapes are described as living landscapes, changing as the culture, climate, and natural surroundings change within and around them. The identity generates by the cultural landscape reflects the "matrix of values" of the society that have shaped it, live within it, and change it as much as its culture changes. Accordingly, the culture itself is the shaping force (Leader-Elliott et al. [6]). That is why the realization of the cultural characteristics and changes of a society remain a key factor to understanding the nature and dynamics of cities' cultural landscape attributes, nature, and reasons for identity change.

Thoughts of Brighton, Brisbane, Chicago, Omsk, Lagos, and Hanôi evoke different feelings and conjure different images of city identity, cultural landscape, and the people who shape it. Street vendors, smells, colors, materials, and structures are all cultural decisions and behavioral selections that define the city's identity. Therefore, man-made city elements and identity are inextricably linked to one another. The two are co-produced as people come to identify with where they live, shape it, and are, in turn, shaped by their environments, creating distinctive environmental autobiographies [7]. Exploring the relationship between place and identity deepens our understandings of identity formation and the role of place in social and psychological development. The bonds between place and identity can influence social formations, cultural practices, and political actions. This may be seen, for instance, in the efforts of groups of emigrants to establish roots in their new homes through the planting of particular tree species or architectural ornamentation (e.g. Mitchell [8]). The literature selected here highlights research from a number of fields in order to show the various and multiple ways in which place and identity intertwine, and the varied stakes in understanding them.

Relations link the city's cultural landscape, and its identity is a key concept in the field of environmental psychology, which suggests that place identity forms in relation to its environmental context. The term was coined by the social psychologists H.M. Proshansky, Abbe K. Fabian, and Robert Kaminoff [13]. They argued that city identity is a sub-structure of a person's self-identity and is formed by the experiences and emotions of our everyday experience of physical spaces. A place identity derives from the multiple ways in which place functions to provide a sense of belonging, construct meaning, foster attachments, and mediate change. Landscape cultural identity is a versatile concept upon which many psychological theories of human-environment relations are built [8], [9]. 


\subsection{Cultural identity conflict}

Cultural conflict occurs when different cultural values and beliefs clash. It is defined on the macro level as "a conflict caused by differences in cultural values and beliefs that place people at odds with one another" (Turner [10]). On a micro level, Alexander Grewe discusses a cultural conflict between guests of different cultures and nationalities, as seen in the British 1970 sitcom, Fawlty Towers [12]. He defines such conflict as one that occurs when people's expectations of a certain behavior coming from their cultural backgrounds are not met, as others have different cultural backgrounds and different expectations (Grewe [12]). Cultural conflicts are difficult to resolve as parties to the conflict have different beliefs. Cultural conflicts intensify when those differences become reflected in politics, particularly on a macro level (Gregory [11]).

Forms of cultural conflict, as a mindset or social and physical behavior, are endured and institutionalized in old Arab cities for other reasons in addition to the effect of globalization influenced by media and communications. Port cities such as Jeddah, Alexandria, and Beirut, where foreign sailors and merchants brought with them their values and cultural habits, expressed social and physical changes in their cultural structures. Changes were also evident in cities placed on the trading routes of caravans, where foreign merchants occasionally settled, interacted with locals, and contributed to the transformation of the locals' cultural profile. However, "cultural conflict" was not a noticeable phenomenon until recently, as communities digested those changes and developed new cultural identity forms. Other cities - Beirut, for example - experienced cultural conflicts in war times, especially amidst civil wars where the need to restore or conserve an intact and acceptable cultural identity which can represent the beliefs and ideology of all previously fought community groups and sects surfaced.

\section{THE SAUDI CULTURAL IDENTITY}

Historically, the social interdependent and collectivistic culture of Saudi society (scored 25 on Hofstede's second index) (Fig. 1) was reshaped under the Ottoman Empire's colonization and cultural supremacy, especially in the Al-Hejaz region and the western zone. The Ottomans exercised prejudiced rule, but could affect all the cultures of the ruled societies in different degrees. The integration of different languages' vocabularies, norms and traditions, economic activities, and architectural styles and urban elements are some examples of such influence. On the other hand, being a Muslim invader, the Arab communities accepted such a cultural influence and the cultural conflict was at its minimum level [1]. The Western colonialization era began with the 1916 Sykes-Picot Treaty through the colonization of the region by the imperial armies of the Western countries [1]. The development of types of weaponries, modern marshal tactics, efficient army structures, and privates' hygiene conduct code brought by the colonization have created a strong association in the local Arabs' mindset between Western culture and modernity, innovation, advanced sciences, and development. Economic development, in addition to the scientific achievements followed the First and Second World War, coupled with the unfortunate setbacks of Arab societies in all life aspects, made the products of the Western culture appealing and socially acceptable. This was articulated further in the Arabs' collective mindset by the incremental impertinence for the traditional values by the new Saudi generations, as such values were never developed to match the speedy change of the global economy and the transition of the world into one interlinked cultural agglomeration. 


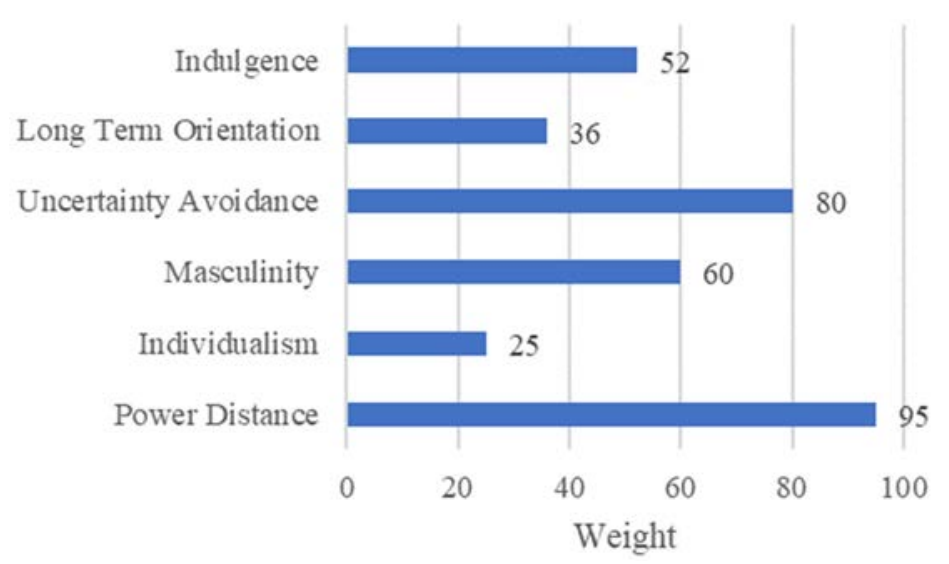

Figure 1: Hofstede's six cultural dimensions of the Saudi Culture. (Source: Magentry et al., 2016.)

A traditionally known character of the Saudi culture is the strong sense of belonging that is generated by the people's ability to understand and accept aesthetics, traditions, heritage, language, religion, ancestry, thinking patterns, and social structures of their culture (Anderson [12]). Nevertheless, such an ability to accept all segments representing the traditional culture widely defers according to each societal group category in relation to age, education level, gender, and the urban-rural living place (Lustig [13]). Some studies note that the existing Hofstede cultural theory indicators, including the two newly added cultural indexes, may not account for the fact that different Saudi individuals and groups will most likely not react to or interpret events, happenings, attitudes, etc. in the same ways as other individuals or groups do. These different individuals and groups constantly increase in number due to external influences, such as the increased exposure to Western culture through overseas education, which has significantly increased in the last decade, and the distribution of social media and other communication measures widely spreading among Saudi youths. While the formal society is bound by traditions, some communities express their rejection for traditions, languages, lifestyles, and local aesthetic values.

The Saudi culture is also a high-power-distance community (scored 95 on Hofstede's first index). The individuals' acceptance of the community's hierarchical order makes management decisions work in only an up-down direction, with no sort of public participation. This is highly recognized at all levels of institutional management, especially at the city management institutions. In addition, the normative nature of Saudi Arabian culture can be seen in its low score of 36 on the Long-Term Orientation dimension of Hofstede's theory. This dimension describes the degree by which societies maintain strong links with their own traditional culture while managing the present and future challenges. People in such societies have a strong concern for establishing the absolute truth. They are normative in their thinking and exhibit great respect for traditions, a relatively small propensity to save for the future, and a focus on achieving quick results.

The Saudi community is categorized as being the most conservative amongst the Arab communities regarding social behavior and lifestyle. Privacy is a critical issue. For this reason, private single-family houses are commonly favorable for middle- and high-income classes and houses generally have very high walls. It is rare to find terraces or wide windows in any residential buildings. 
Nevertheless, society was different before the 1980s. A major cultural shock overwhelmed the Saudi society upon the Grand Mosque seizure in November-December 1979, when extremist insurgents calling for the overthrow of the House of Saud took over Masjid al-Haram in Mecca. The seizure of Islam's holiest site shocked the Islamic world as much as the Saudi community. Following the attack, the Saudi state implemented a stricter enforcement of Islamic code and the Saudis themselves became more conservative. However, comparing Jeddah, culturally, to two other Saudi Primate cities, Al-Riyadh and Al-Dammam, reveals a slight difference in the cities' social practices, interpreted as cultural differences. This is seen in the ethnically diversified city population of Jeddah, where $48.7 \%$ of the population are aliens of multiple origins, while the average is $31.24 \%$ for the total country. Ethnic diversification has derived from the historical role played by the city, as the major gate for Muslims' holy destinations and a major hub for trade and industry, which makes it a favorable place to settle in for foreigners. However, the social patterns of the Jeddah community maintain the conservative "appearance" nature of the Saudi society. The rigidity and intolerance of the Saudi rule suppressed attempts to express social cultural changes openly. Attempts for basic practices, such as women driving cars, have been met with strict rejection by the government as well as by many individuals. However, the same community permits women to drive cars in some "gated" communities or in the deserts.

\section{THE CULTURUAL LANDSCAPE OF JEDDAH}

Jeddah is the first port city and the second biggest city in Saudi Arabia, with a current urban area of $1690 \mathrm{~km}^{2}$, located on coast of the Red Sea. Historically, it has been a commerce hub and a gateway for pilgrimages to the Islamic holy cities Mecca and Medina. Anyone who approaches Jeddah by plane for the first time will be impressed by the huge urban expansion that forms the city's bulk. However, less than 4 million inhabitants live within the metropolitan premises. The city's current urban morphology is composed of two vastly different urban forms: the new city to the North and the old city to the South. These different forms also reflect social and ethnic divisions: the poor live in the South and the affluent live in the North. Some districts, mainly located to the South, accommodate ethnic groups such as "Al Hendawia", "Al Rewais", and "Bani Malek", which are favorable residential districts for poorer Indians, Bengalis, and Africans. However, some lower-class and poorer Saudis can be found in these declined and environmentally deteriorated neighborhoods. High-class and Hejazi Saudi families used to live in the historic old part but moved upward to the North with the expansion of the city.

\subsection{The old city}

The old city (Albalad), currently known as the Historic District, dates back to the 7th century, and expresses a traditional form of Hejaz architectural style and urban form. This traditional city's form evolved as a redefined building art and passive technology. As Jeddah was an important trading port, and thus a cross-cultural agent between the Middle-Eastern, Asian, and Europeans traders, it contributed to forming a special version of the Hejazi style and urban form of old Jeddah. The old city retains human-scaled spaces and traditional homes built from coral, timber, and limestone (Figs. 2 and 3). Its different spatial nature and the character of its buildings make it looks like "a city within the city". 


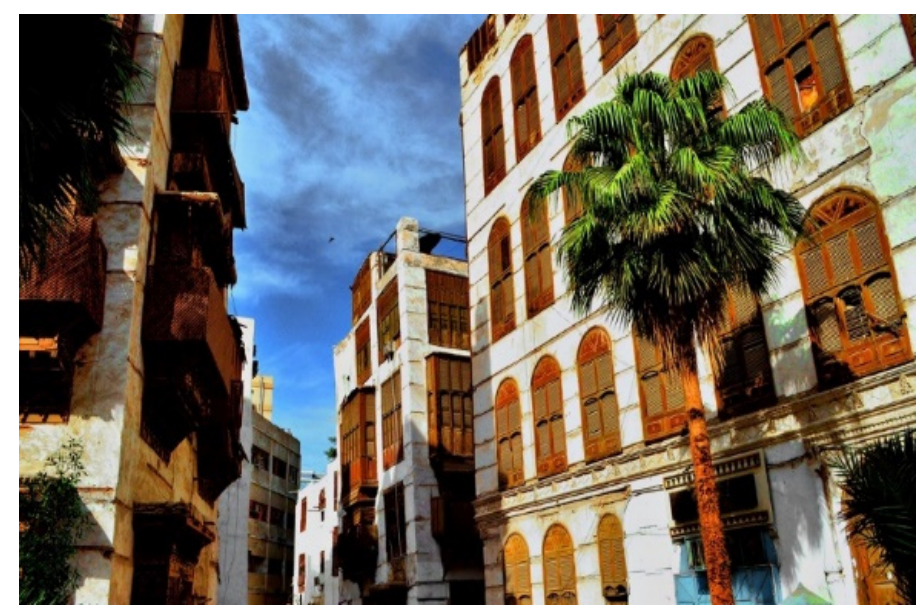

Figure 2: Current street and buildings of Al-Balad District. (Source: Author, 2017.)
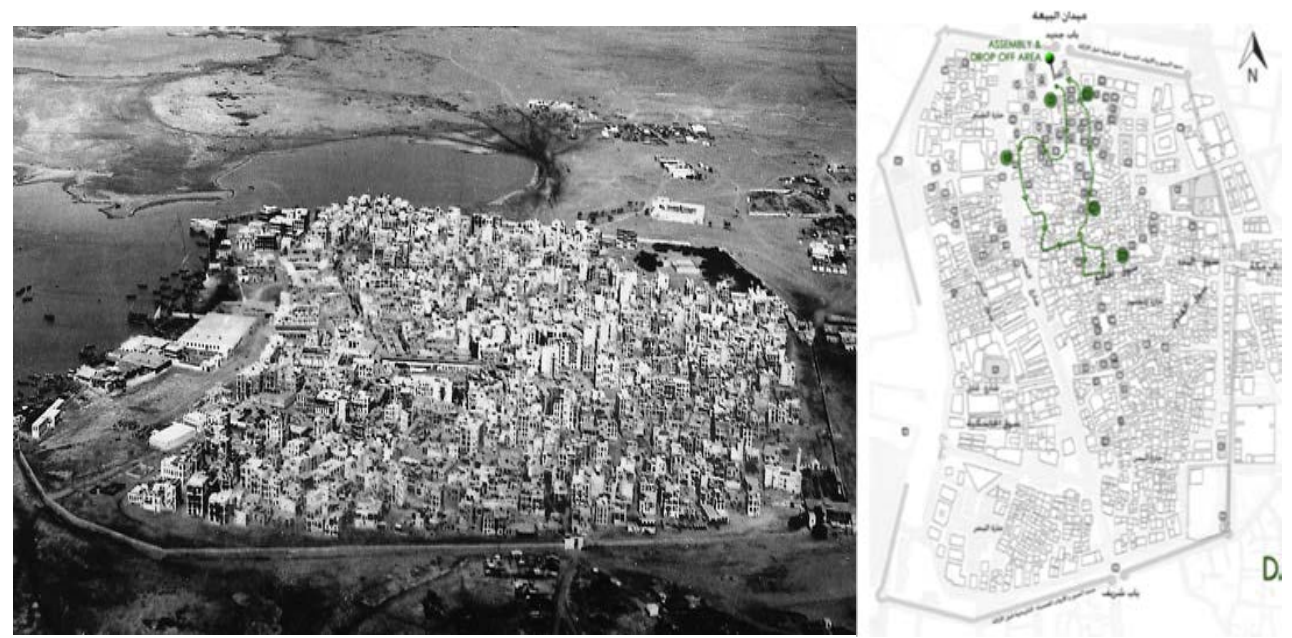

Figure 3: The old city of Jeddah. Currently Al-Balad District surrounded by walls of 1932 . (Source: Makhlouf, 2009.)

\subsection{The new city}

The new part mainly expands to the North of the old city and is usually called "The New City". Emerging in the late 1930s, and due to the effects of the oil boom period of economic growth, the city's intense urbanization was a viable solution to accommodate the new rural-urban and expatriates migration movement to Jeddah (Harris [14]). The major Master Plan of Jeddah, put forward by Dr. Abdulrahman Makhlouf in 1962 (Fig. 4), continues to be the base for the Jeddah expansion plan today (Fig. 5) (Makhlouf [15]). The longitudinal main arteries connect the old part with the new occidental-styled urban developments. The 


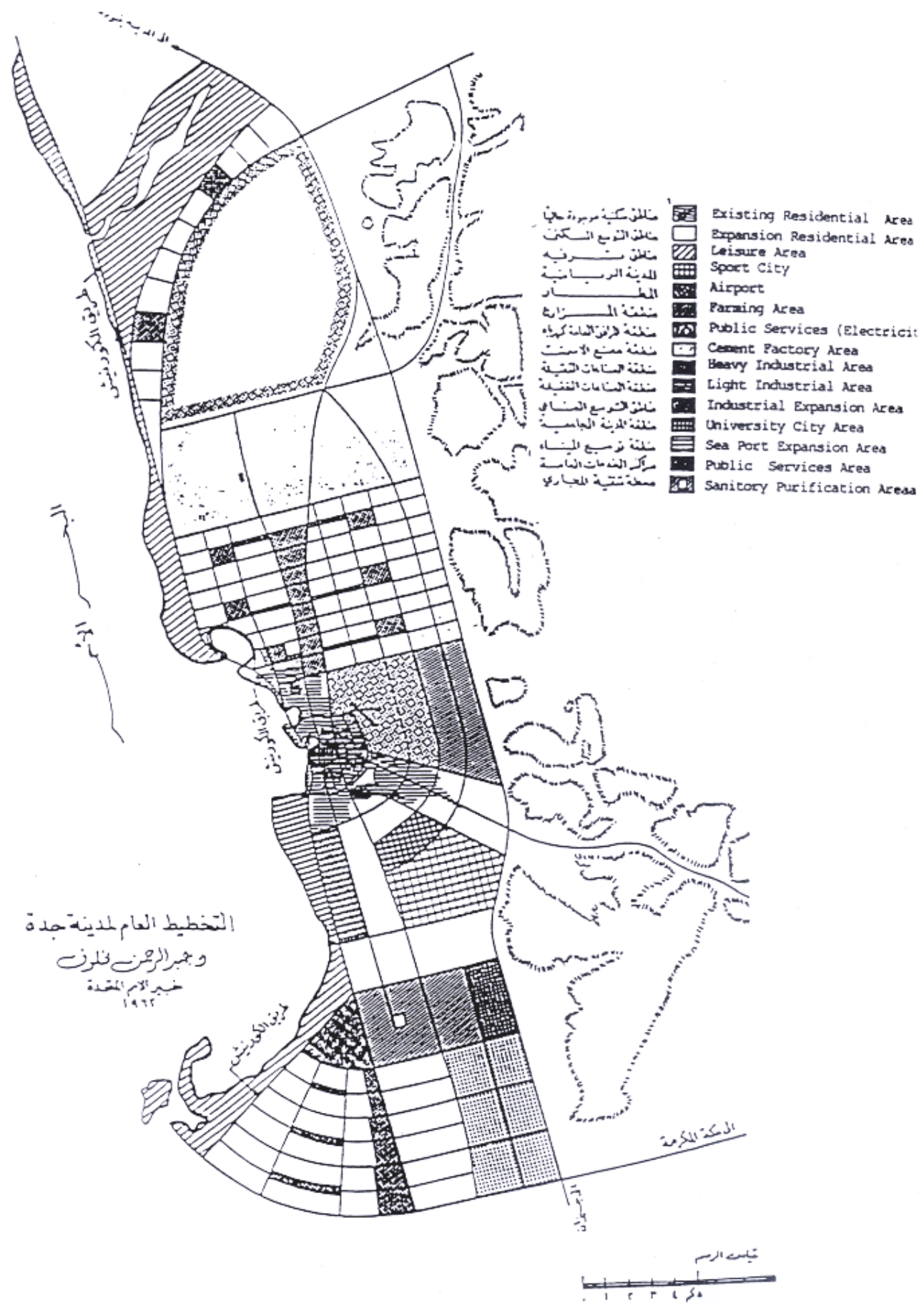

Figure 4: 1963 Jeddah City's Master Plan by Dr. Makhlouf. (Source: Makhlouf, 2009; Harris, 1990, 2012.) 


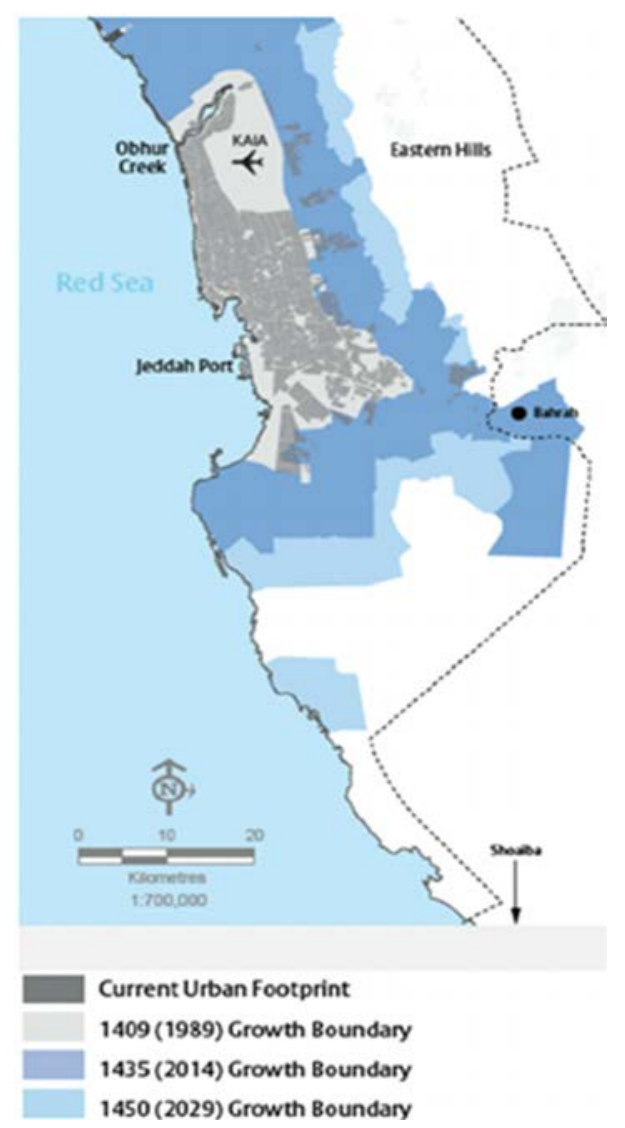

Figure 5: Jeddah growth prediction map from 1989 to 2029. (Source: Magentry et al., 2016.)

increasing rate of car ownerships has made this structure a viable base for development schemes which are characterized as being low-density, sprawled, loose, and totally exclude pedestrian integration with public outdoor spaces. Another reason that has contributed to this urban structure is the intensification of the "White Land" phenomenon, which is essentially buying vacant land only to keep surplus wealth from value depreciation if it is stored in commercial banks. To compensate for the inner-city "frozen" land, the local government continues to provide new urban land to the North, adding more thrust to the sprawling nature of the city.

Comparing the new city's spatial form to the historic and transitional zones (the intermediate district between the old part and the new part) reveals a drastic spatial urban transmission. The new city persistently reflects a "Westernized" model of urban planning and diverging architectural styles and designs. Resort hotels, private beaches, and outdoor sculptures line the 12-km-long seafront promenade (Corniche). The new city's spatial structure is dominated by private cars and traffic. This results in excessively long inner roads, high car speeds, and inhumanly scaled spaces. Additionally, such wide and high-speed longitudinal arteries physically and visually bisect the city into urban strips and result in decreasing horizontal connectivity. 
Jeddah's cultural landscape has been "exoticsized" by the idea of modernity. Therefore, the traditionally separate meanings between authentic and inauthentic traditional cultural landscapes have been blurred. The Saudi version of modernity is exemplified by its boxed avant-garde architecture, excessively widening roads with higher-speed vehicles, mega-scale roundabouts, western models of parks and green areas, iron perpendicular grid planning and separate land uses (Figs 6-8). This idea of modernity also meant the elimination of traditional architectural and urban vocabularies in the new developments of the city.

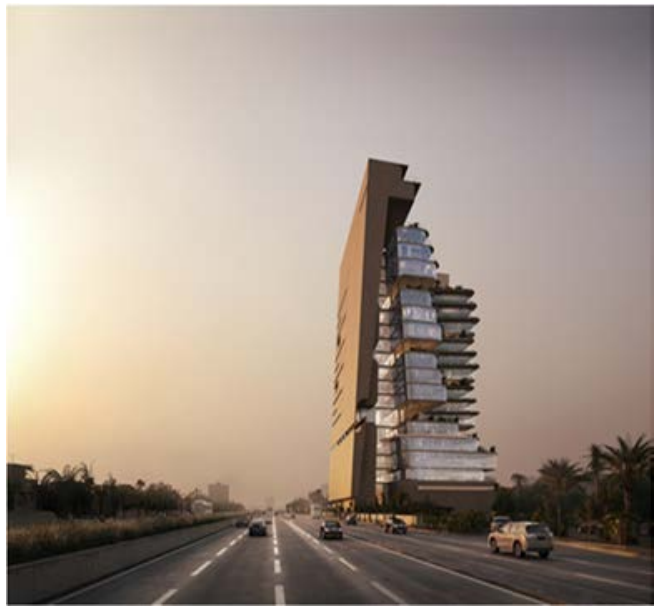

Figure 6: Abdullatif Jamil Corporate Headquarters in Jeddah Harbor district by Andrew Bromberg of Aedas. (Source: Arch Daily, 2017.)

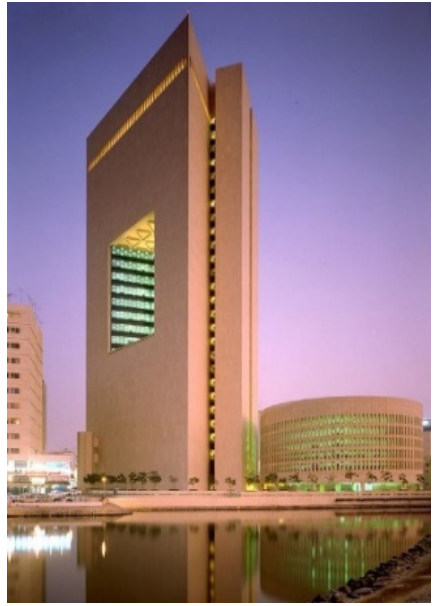

Figure 7: The late-Modern National Commercial Bank in Jeddah by Gordon Bunshaft. (Source: Carosfeksi, 2015.)
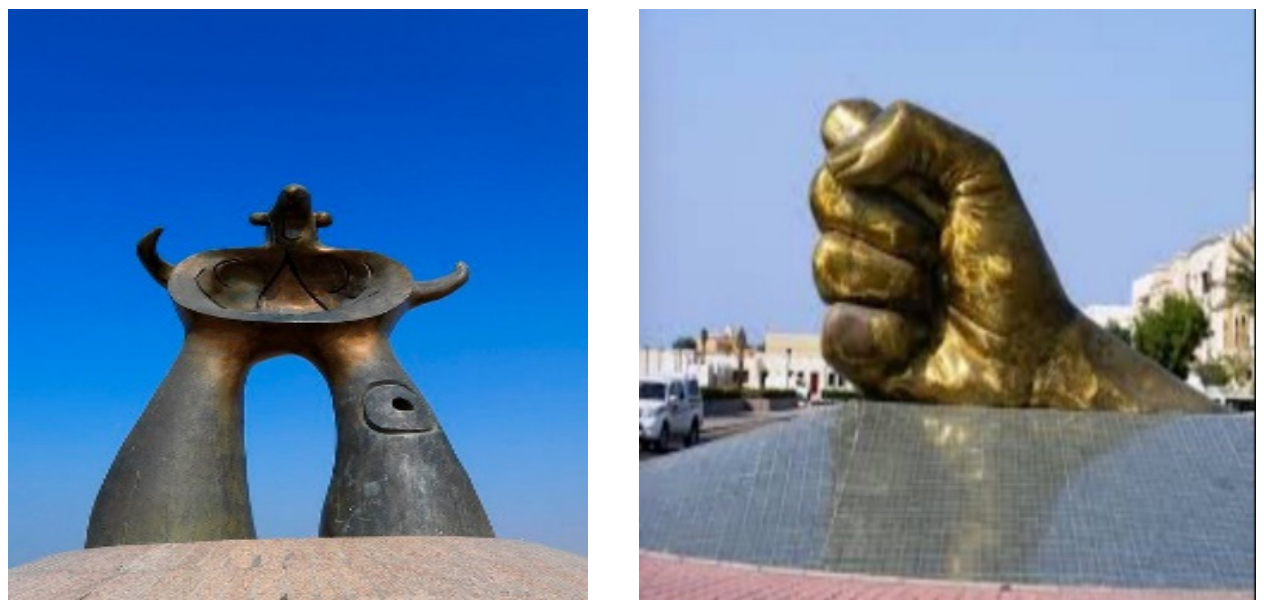

Figure 8: Jon Mario sculpture in Jeddah's open-air museum. (Source: Author, 2017.) 


\section{FACTORS OF CHANGE}

\subsection{The vulnerability of the urban system}

The deficiency of the urban system and the lack of a coherent national planning strategy in Saudi Arabia has led to a regional disparity and an acute urban polarization accompanied by high rates of urbanization in its primate cities. This was also accompanied by the obvious incapacity of the urban management system to undertake reasonable and well-structured urban management decisions. The percentage of the country's total population living in primate cities rose from $12.56 \%$ in 1960 to $41 \%$ in 2009 . The capital Al-Riyad seized more than $22 \%$ of this total urban population, followed by Jeddah $(33 \%)$. The urban population in Jeddah has grown rapidly from 1970 to 2002 to an estimated population of 2,867,4460 at an average annual growth rate of $12.43 \%$. Accordingly, Jeddah increased more than 30 times in only 35 years (Davidson [16]). While Saudi Arabia failed to rectify imbalances in its urban system for many different reasons, national and local governments devoted their resources to provide urban land for the cities' growth as a viable solution for its over-urbanization problems. For Jeddah, as well as for all Saudi major cities, the urban growth rate escalated rapidly upon the discovery of oil, which initiated a drastic change in the Saudi economic profile at both micro and macro levels. Huge oil revenues, induced by the 1973 war, enabled the governments of Gulf countries to allocate more financial resources to infrastructure and housing projects. Decision-makers, with the non-existence of a national development plan, were tempted to concentrate investments and wealth in primate cities such as Jeddah, Al-Riyadh, and Al-Dammam (the capital of oil industry in KSA), which empowered the dynamics of urban change, adding more thrust to the imbalances of the total urban system.

\subsection{Globalization and modernity}

One major understanding of globalization is as "The globalization of capitalism, achieved in its cultural aspect via a Western-dominated media system" [17]. This complex, multidimensional conceptualization, which views globalization as operating simultaneously and interrelatedly in the economic, technological, communicational, political, and cultural spheres of human life, is in fact relatively consistent with academic discourses. However, the cultural implication of globalization is that it involves not the simple distribution of a particular Western lifestyle, but a more complicated dissemination of the entire range of institutional features of cultural modernity. Considering this view of globalization in the Arab region context, the influence of globalization has manifested unevenly in the physical constituents of the urban context in all Arab nations in two major ways: the change of urban context and morphology, and the emergence of diverse architectural styles, resulting in the appearance of a "disordered" identity of the cities.

Modernity, by definition, institutionalizes and regulates cultural practices, including the process of inviting other forms of cultural consumerism patterns [18]. However, such new forms are subject to be consumed within a broader context which interlinks these new forms of cultural practices and decisions into a consistent matrix of technological, environmental, and chronically interrelated incrimination processes. Within the context of Saudi Arabia, the effect of socially and culturally related decisions and changes, especially those associated with modernity, is minimal and exclusive to only physical forms rather than regulating cultural practices and norms. The importation of work by Western architects, like Andrew Bromberg of Aedas, Foster and Partner, Ricardo Boffil, Mossessian Architecture, Adrian D. Smith and Matteo Nunziati, who were encouraged to undertake development 
projects in the new city of Jeddah, exemplify avant-garde, cosmopolitan-styled designs and overlook the environmental and local social values and considerations [19]. Such an occidental architecture and urban design approach has been met with acceptance and encouragement by most of the Saudi decision-makers and by multiple sects of the society, especially the youths, calling for "Modernity". Private residences and residential and commercial buildings by the private sectors were left to choose alien and, usually, odd architectural styles all over the city. Roman, Greek, Hegazi, Neoclassic, Ultramodern, Indian, Chinese, and other styles were permitted by the deficient urban ordinance and building code of the city to be constructed adjacent to each other in the same street of each new neighborhood.

\section{CONCLUSION}

An examination of architectural and urban attributes' styles and models in Jeddah metropolitan city reveals a blurred and chaotic cultural landscape identity, especially between the old and new parts of the city. The incapacity to maintain an intact cultural-landscapeidentity formation is attributed to the change of the community's collective mindset towards the interpretation of the "identity" and "locality", and the link between "modernity" and "Westernization". Such a society's cultural change and failure to develop a local expression of "modernity" is evident by examining the typology of architectural and urban model preferences of the residents, urban officials, and decision-makers. The urban system's vulnerability in terms of the schemes of new developments, urban management policies, tools, and human technical resources is another contributing factor in such cultural identity discrepancy. The inefficiency and primitivity of urban ordinances and building codes continue to form low-density, loose, and built-up areas, with a unique and fully car-independent urban pattern.

Driven by cultural transmission forces, three approaches can be identified for a new "form" of cultural identity of Jeddah. The first is the reproduction of the past models, which asserts the adherence to the past as a source of values. The second is the total rejection of the past models and any relationship with them and impersonating Western forms that adhere to the image of what so-called "modern values" are. The third approach is more sophisticated; it extracts the core values of the tradition and develops a new formula that encompasses in its core the traditional values, but blends them with the necessary aspects of modernity.

\section{REFERENCES}

[1] Ragab, T.S., The crisis of cultural identity in rehabilitating historic Beirut downtown. Cities, 28, pp. 107-2014, 2011.

[2] Hofstede, G., I, we, and they. Readings in Intercultural Communication: Experience and Contexts, eds J.N. Martin, T.K. Nakayama \& L.A. Flores, 2nd ed., McGraw-Hill, pp. 289-300, 2002.

[3] Fromkin, D., A Peace to End All Peace: Creating the Modern Middle East 1914-1922, Henry Holt: New York, 1989.

[4] Sicker, M., The Middle East in the Twentieth Century, Praeger Publishers: Westport, CT, 2001.

[5] ICOMOS, 15th General Assembly and Scientific Symposium, 17-21 October. Final Report, www.icomos.org/xian2005/resolutions15ga.htm. Accessed on: 11 Dec. 2017.

[6] Leader-Elliott, L., Richard, M. \& Heather, B., Understanding cultural landscapes. Discussion paper, www.academia.edu/2855898/Understanding_Cultural_Landscapes. Accessed on: 12 May 2017. 
[7] Gieseking, J. \& Mangold, W. (eds), The People, Place, and Space Reader, Routledge: New York, 2014.

[8] Nation Master, Saudi Arabia density and urbanization stats. www.nationmaster.com/country-info/profiles/Saudi-Arabia/People/Density-andurbanisation. Accessed on: 13 May 2018.

[9] Katz, C., So what you know: The struggle for social reproduction in rural Sudan. Annals of the Association of American Geographers, 81(3), pp. 488-514, 1991.

[10] Saegert, S., What we have to work with: The lessons of the task force surveys. No More "Housing of Last Resort": The Importance of Affordability and Resident Participation in Rem Housing, eds S. Saegert, M. Cotton \& D. Reiss, The Task Force on City Owned Property: New York: pp. 35-63, 1996.

[11] Turner, J.H., Sociology, Prentice Hall, p. 87, 2005.

[12] Grewe, A., “I'm Sick to Death With You...” or External Character Conflicts in Fawlty Towers, GRIN Verlag, p. 10, 2005.

[13] Proshansky, H., Abbe, F. \& Kaminoff, R., Place-Identity, 1983.

[14] McLuhan, M., The Network Community: An Introduction to Networks and Global Village, Aberystwyth University Press, p. 62, 1995.

[15] Makhlouf, A. \& Katz, L., Negotiating international business - Saudi Arabia. The negotiator's reference guide to 50 countries around the world. www.globalnegotiationresources.com/cou/SaudiArabia.pdf. Accessed on: 14 Aug. 2016.

[16] Hamamura, T., Approach-avoidance motivation across cultures. https://circle.ubc.ca/ bitstream/handle/2429/1012/ubc_2008_fall_hamamura_takeshi.pdf?sequence=1. Accessed on: 22 Sep. 2016.

[17] Tomlinson, J., Globalization and Culture, The University of Chicago Press, 239 pp., 2003.

[18] Liu, L. \& Zhao, E., Research into culture difference of attribution theory, www.seiofbluemountain.com/upload/product/200911/2007qyczhy1z4a2.pdf. Accessed on: 4 May 2016.

[19] Ting-Toomey, S., Intercultural conflict competence. Readings in Intercultural Communication: Experience and Contexts, eds J.N. Martin, T.K. Nakayama \& L.A. Flores, 2nd ed., McGraw-Hill, pp. 323-335, 2002. 